\title{
Strategies Hospital Manager Use to Improve Customer Services
}

\author{
Delores J. Leonard1, Charles Needham ${ }^{2,3}$ \\ ${ }^{1}$ Western Governors University, Salt Lake City, UT, USA \\ ${ }^{2}$ Jarvis Christian College, Hawkins, TX, USA \\ ${ }^{3}$ Liberty University, Lynchburg, VA, USA \\ Email: deloresjleonard@gmail.com, charlesneedham@yahoo.com
}

How to cite this paper: Leonard, D.J. and Needham, C. (2020) Strategies Hospital Manager Use to Improve Customer Services. Open Journal of Business and Management, 8, 820-854.

https://doi.org/10.4236/ojbm.2020.82051

Received: February 17, 2020

Accepted: March 20, 2020

Published: March 23, 2020

Copyright $\odot 2020$ by author(s) and Scientific Research Publishing Inc. This work is licensed under the Creative Commons Attribution International License (CC BY 4.0).

http://creativecommons.org/licenses/by/4.0/

(c) (i) Open Access

\begin{abstract}
The purpose of this study was to explore strategies for hospital managers to improve customer services. The target population consisted of five hospital managers who implement customer services strategies within hospitals. The conceptual framework for the study was the expectation-confirmation theory. Using methodological triangulation, the data derived from included semistructured interviews, hospital policy and procedure documents, and qualitative data from the Consumer Assessment of Healthcare Providers and Systems (HCAHPS) Hospital Compare website. The three major themes were to improve interpersonal communication, address issues in the hospital environment, and provide employee training. The findings reveal that exploring employee training relates to the conceptual framework of the expectation-confirmation theory. The participants described multiple attempts to alter operations within the hospital based on customer expectations for satisfaction and to confirm customer satisfaction for the hospital system. The expectation confirmation theory by Joo, Park, and Shin (2017) [1] was the framework of this study. Hospital managers performed actions for example, hiring the right people, using customer feedback for improvement, and using the HCAHPS qualitative data to create strategies that would meet customer expectations for satisfaction and loyalty.
\end{abstract}

\section{Keywords}

Affordable Healthcare Act, Company Culture, Competitive Advantage, Customer Experience, Customer Oriented Approach, Customer Service, External Customer, Front Line Employees, Internal Customer

\section{Introduction and Background}

Healthcare professionals have many challenges providing satisfactory customer 
service to patients. One challenge that health care professionals encounter is that patient views are too subjective making them redundant in determining quality customer service [2]. Another challenge is the ability of a healthcare provider to understand and view the patient as a customer with service needs other than patient care [3]. Service providers' personality traits reflect the way they deliver customer service (Handa \& Gulati, 2014) [4]. Healthcare is a consumer-oriented market. Patients have a choice when selecting services and hospitals for care in the competitive healthcare market. Hospital managers must develop strategies to engage hospital staff in patient interactions. In addition, hospital managers must develop a consumer-orientated market [5].

The lack of customer service in healthcare links to unclear organizational values and the failure of communication to employees of organizational goals [6]. Patients demand quality healthcare and service when spending money, especially when considering the rising costs of healthcare and the decrease in payments for services by insurance companies [7]. Although a recent improvement in services and products exists, employee engagement in service encounters decreased [8]. Miller (2014) [8] described, 70\% of workers are not engaged in improving their work or interactions in the workplace. The poor quality of customer service causes an organization to lose customers, obtain a poor corporate image, and lose profitability [9]. Failures in service provider ability to deliver quality customer service in healthcare are worldwide including the United Kingdom, Australia, and the United States [10]. Hellen and Saaksjarvi (2011) [2] indicated a shortage of research exists in healthcare in regards to the delivery of customer service.

\section{Problem Statement}

Many customer service strategies of healthcare managers fail to satisfy patient demands causing a lower quality of customer satisfaction [10]. Approximately $80 \%$ of top-level managers said organizational employees provide excellent customer service, but only $8 \%$ of their customers support the claim of having an excellent experience [11]. The general business problem was that the strategies implemented by hospital managers are inefficient to increase customer service leading to less customer satisfaction and revenue losses. The specific business problem was that some hospital managers lack strategies to improve customer service.

\section{Purpose Statement}

The purpose of this qualitative exploratory single case study was to explore the strategies used by hospital managers to improve customer service. The population for the study included five hospital managers from a Nevada hospital system who implement customer service strategies improving customer satisfaction. Identifying customer service strategies by hospital managers will provide other hospital managers with the knowledge to improve hospital performance. Strategies provide by hospital manager can help other managers implement new strategies or improve existing strategies for patient-focused customer service 
leading to improved overall customer experience in healthcare.

\section{Research Question}

The Central research question guiding this study was what strategies do hospital managers use to improve customer service? Data derived from semistructured interviews, documents of hospital policy and procedures, and HCAHPS qualitative data from the Hospital Compare website.

\section{Assumptions, and Delimitations}

\section{Assumptions}

Assumptions are common understandings not verified, yet considered true [12]. Several assumptions affected the exploratory case study. The first assumption was that five healthcare managers, willing to participate in the study were easy to find. The second assumption was that healthcare managers would provide in-depth information on strategies for customer service. The third assumption was the results of the study would contribute to the understanding of customer service by healthcare managers allowing healthcare managers the opportunity to make a difference in customer service. The fourth assumption in qualitative research studies is that interviews can provide data that is truthful and useful when exploring an issue [13]. The fifth assumption was the participants would provide information to make a difference in customer service in healthcare.

\section{Delimitations}

Delimitations restrict the scope of the research study and define the boundaries; however, delimitations are in the researchers' control [12]. The boundaries set for the study delimited to hospital managers who (a) work in a hospital, (b) live in Nevada, and (c) are decision makers for customer service strategies. The importance of reporting the strategies of customer service included several factors for example, motivation and encouragement of employees. Hospital managers delimited the study because hospital managers formulate the goals set forth for hospital staff to follow [7].

\section{Significance of the Study}

\section{Contributions to Business Practice}

Hellen and Saaksjarvi (2011) [2] reported healthcare is an adverse service because the outcomes are sometimes unpleasant. Hellen and Saaksjarvi [2] suggested healthcare investigators rarely consider healthcare when reporting customer service because the perception is that patients evaluate experiences on feelings rather than their service experience. Customer satisfaction, including customer service, is a subject of discussion and interest in marketing for decades [14]. A service provider's inefficient customer service affects the customer and the success and profitability of the organization [15]. As healthcare becomes a more competitive market, and hospitals receive payments reflecting customer satisfaction, hospitals should focus on providing excellent customer service [16]. The findings of the research study may provide hospital managers with strategic 
ideas to improve customer service in the hospital. Healthcare providers are aware of the strategies to deliver excellent customer service. Healthcare administrators are aware of the strategies healthcare managers use to provide good customer service to patients and customers. The awareness of effective customer service strategies may provide useful information for implementation of new customer service strategies by managers for healthcare providers to improve customer satisfaction.

When customers receive poor customer service, organizational managers risk losing loyal customers, new customers, funding, profits, competitive advantage, and reputation [16]. Information regarding a hospital manager's strategies of customer service can help hospital leaders' work simultaneously when implementing new customer-focused strategies to reduce dissatisfied customers and patients. The healthcare industry will improve the hospital environment, and hospitals managers will meet the Affordable Care Act (ACT) guidelines by providing a higher quality of customer service

Implementations for Social Change

Makarem and Al-Amin (2014) [17] described healthcare as consistently growing and becoming more competitive. Therefore, understanding the customer service strategies by hospital managers to ensure customer satisfaction is essential to the success of the hospital. When hospital managers implement appropriate strategies for customer service, patient satisfaction might increase. The study results will contribute to positive social change by identifying customer service strategies to improve customer satisfaction. Consequently, stronger patient satisfaction builds confidence in healthcare [18]. When hospital managers create a patient and customer focus culture, patients and customers in healthcare benefit environmentally, socially, and economically regarding their healthcare [18].

\section{A Review of the Academic Literature}

\section{Expectation Confirmatory Theory}

The expectation-confirmation theory, by [19] Richard L. Oliver (1980), has concepts of expectations, performance, confirmation, satisfaction, and repurchases intentions [20]. The expectation-confirmation theory was the main conceptual foundations in the study. The theory includes expectations of customer service and includes factors that make a customer service experience satisfying. Understanding the factors that influence the delivery of excellent customer service is an essential part of obtaining new customers and earning loyal customers [21].

The understanding of expectations of the company culture, personality traits, and job satisfaction is necessary to provide good customer service [22]. Handa and Gulati (2014) [4] revealed personality is an important role for an individual to have a successful occupation; however, personality and other factors impact employment related outcomes. The importance of research in customer service 
is to determine the expectations of a service provider's personality in displaying excellent service [4]. Company culture and job satisfaction are additional aspects of a service provider's ability to provide excellent customer service [23]. Organizational leaders should have concerns regarding the well-being of the employee and customer [22]. The employee is the representative of the organization, and the customer is the primary market [22].

When customer expectations are successful (confirmation), customers are satisfied [24]. When customer expectations are not satisfactory (disconfirmation), customers are not satisfied [24]. S. Y. Chou, Kiser, and Rodriguez (2012) [25] explored medical tourism using the expectation-confirmation theory. S.Y. Chou et al. [25] investigated the expectations, performance, confirmation, satisfaction, and intentions of medical tourists to continue the use of overseas medical services. Hsu and Lin (2015) [26] used the expectation-confirmation theory to explore value and satisfaction of mobile phone users regarding mobile applications. The perceptions of mobile users are in the areas of expectations, confirmation of the expectations, and the intention to purchase paid applications [26]. A determining factor of customer satisfaction is the customer confirmation [20]. Understanding the hospital manager's strategies of customer service helped reveal what was necessary to ensure customer satisfaction and increase HCAHPS scores.

\section{Customer Service Philosophy}

Customer service is an organizational philosophy of activities created to enhance customer satisfaction while assisting organizational leaders in generating revenue and income [27]. Customer service is a major part of the service industry, which includes healthcare [28]. Customer service not only influences customers but also affects employees and organizations both negatively and positively depending on customer outcomes [29]. Previous research studies exist with the effects of customer service on customers and organizations.

In the past 30 years, several studies exist reflecting on the customer and patient satisfaction in healthcare [30]. A limited amount of research studies included the effects of customer service in a healthcare setting. The themes of previous research included in the review of the literature-included theory, customer oriented approach, customer relationships, and job satisfaction. Other topics included customer and service provider behavior, customer satisfaction, the perception of customer service, customer service in healthcare, and a summary of the literature. The organization of the literature review is from past research, descriptions, potential themes, and exploration of customer service and the effects of customer service in the service industry including healthcare.

\section{Customer Service}

The idea of customer service began in the 1960s. Customer service includes customer perspectives of the consumer and strategies of the provider [21]. Customer service is a process added by the service industry to shape and influence customer perceptions of their service experience [31]. To provide excellent cus- 
tomer service is a necessity in the organizational manager's ability to maintain customer satisfaction and loyalty, meet profitability goals, and obtain a competitive advantage [32] [33]. Green (2014) [34] stated that customer service is difficult to measure because customer service includes customer expectations, and every customer has different expectations. A customer will rate the customer service experience on expectations of the service provider's ability to meet the expectations [2].

Gummesson (2014) [35] focused on the growth of service management and marketing by exploring relationships with service providers and customers. Gummesson [35] found that as years progress the need for service providers and customers to form relationships is crucial to the success of a service organization. Kondasani and Panda (2015) [36] explored customer service by exploring how perceived service quality and customer satisfaction in healthcare lead to customer loyalty. Customer and service provider relationships, interactions, and the quality of facilities positively affect the healthcare customer perception of service quality [36]. Excellent customer service is essential for staff to form relationships with customers and maintain a loyal customer base [37]. Staff must work beyond customer expectations for customers to remain loyal [37]. Ekiyor et al. (2010) [21] explored customer service relating to obtaining loyal customers. Gaining a new customer is 5 times more expensive than maintaining an existing customer. Therefore, loyal customers are essential to the success and growth of any organization [21].

\section{Customer Oriented Approach}

\section{Customer Relationships}

Oluseye, Tairat, and Emmanuel (2014) [38] reported that business corporate decision makers are aware that excellent customer service is critical to building relationships with customers. The concept of relationship marketing is for organizations' staff to develop relationships with customers by providing excellent customer service and satisfaction beyond advertising and sales [21]. Customer relationship strategies help organizational leaders make connections with customers through communications generating customer focused products and services [39]. The goal of managing customer relationships is to improve customer experiences that lead to customer satisfaction, loyalty, and profit for the organization [40] [41]. If customers are happy, customers will establish a long, trusting, and loyal relationship with the organization [21]. Narteh, Agbemabiese, Kodua, and Braimah (2013) [42] indicated that marketing researchers view customer relationships and loyalty as a currency in the marketing place for the $21^{\text {st }}$ century. The cost of maintaining loyal customers is much less than the cost of obtaining new customers [42].

Shahraki (2014) [43] indicated that organizational decisions makers must realize the essential requirement in developing organizational goals is customer satisfaction through building trust and relationships with customers. Establishing relationships with customers is the most cost-effective way for organizational 
decision making to maintain a high level of customer loyalty [44]. The use of relationship marketing validates trustworthy behavior between supplier and purchaser in successful partnership [45]. Marketing experts link building respect and rapport as successful strategies for developing relationships with customers [44]. A review of marketing research literature includes customer commitment and trust as two important factors in building relationships with customers [46]. Organizational decision makers who focus on commitment to customer needs will earn the trust of customers and maintain a lasting relationship [47]. When customers receive satisfaction, they will share the experience with other people [48]. Customers who have a good relationship with the service provider have a positive and satisfying experience [44]. When a customer is satisfied, the results can lead to positive word-of-mouth networking, which can enhance an organization's image, securing repeat customers, and increasing revenue [9]. In a hospital setting, a patient perception of quality accounts for approximately $27 \%$ of the variation in financials for example, revenue, earnings, and the return on assets [9].

\section{Organizational Leaders and Management Role}

Managers who help develop employees to their fullest potential are influential in promoting the quality of service employees deliver to customers [49]. Organizational leaders have a significant role in creating a positive culture and environment for employees [50]. Role prescribed performance is an employee fulfilling the role of the position [51]. Extra-role performance is an employee performing beyond the expectations of the position. Employees display extra-role performance when organizational decision makers promote a culture of transparency in communication and employee creativity in the work environment [51]. Employees are more willing to work harder for the organization when they experience a positive work environment [52].

Organizational leaders establish the culture and environment through the goals of the organization [50]. Service quality is a primary concern for organizational decision and policy makers [53]. Organizational decision makers do not serve customers equally because of limited resources [54]. In the service industry, customers have different reasons and use for purchasing and may have various encounters and experiences. All customers have different needs, so customers receive different but fair treatment [54].

Service provider behavior. The service industry includes $94.6 \%$ of all added jobs between 2014 and 2024. Service jobs will include 9.3 million new jobs, and 3.8 million new jobs will apply in the social assistance and healthcare field [55]. Service providers are front line employees at the forefront of the organization and the first individuals that customers have contact [56]. Customers often link a service provider's behavior to the rating of the customer service experience [28]. A provider's social skills, values, and organizational commitment are traits that positively affect the customer experience [57]. A service provider's interactions with customers are critical to customer satisfaction, loyalty, and organiza- 
tional success [4].

\section{Customer Satisfaction}

The increased competition in the global market makes customer retention and loyalty an important objective for organizations [56]. Increasing levels of customer satisfaction through relationship building means positive benefits for organizational decision makers [58]. Customer loyalty is a link to customer perceived quality, satisfaction, and trust [56] [58]. Mathies and Burford (2011) [28] conducted a qualitative study of 800 frontline workers from different areas of the service industry to explore gender differences in the perceptions of customer service. Male employees perceive customer satisfaction as the outcome of the entire interaction, and female employees perceive customer satisfaction as emotional results and interactions with the customer. The overall perception of customer service by both male and female employees include the idea that customer satisfaction aligns with listening to the customer and making the customer happy. Highly skilled employees who are committed to their organization have a better ability to satisfy the customer [52]. Skilled employees rated higher in customer satisfaction. Emotionally competent employees have a better opportunity of ensuring customer satisfaction because of their ability to establish a rapport with the customer [59].

Customer Loyalty

Retaining existing customers is cheaper than the cost of attracting new customers [60]. Customer service is a primary source of maintaining repeat customers also known as loyal customers [61]. Customer loyalty is a link to many factors for example, service quality, customer satisfaction, corporate image, and relationships [58] (Richard \& Zhang, 2012) [63]. Customer loyalty is a direct result of customer satisfaction [62]. Richard and Zhang (2012) [63] described researchers as focusing mainly on service quality and trust when exploring customer loyalty, and only a few researchers focus on customer loyalty relating to the corporate image. The corporate image is an individual's feelings and beliefs regarding an organization and is the final impression a customer feels towards an organization [63]. Trust and commitment are important factors in customer loyalty because trust and commitment are sources of relationships between the customer and provider [46]. Corporate image although limited in research is also a primary source of customer loyalty because a company's reputation influences customer loyalty [63]. Customer loyalty and customer service relate because when a customer experiences good customer service from a provider, the customer will use the service again [46].

\section{Customer Service in Healthcare}

In the growing healthcare industry of economic and social importance, Hellen and Saaksjarvi (2011) [2] agreed that researchers should place the concern on healthcare because people are living longer and in need healthcare services. Hellen and Saaksjarvie [2] suggested many researchers report adverse services are unpleasant to experience because customers base customer service experience on 
feelings rather than the service outcome. Alrubaiee and Alkaaida (2011) [9] reported good service and relationship building as factors in a customer perception of quality service. In previous years, hospitals received ratings by the quality of medical services they provide [64]. In the healthcare industry, a satisfying customer service experience must include customer involvement in the decision-making process [65].

\section{HCAHPS Patient Satisfaction}

The United States healthcare system personnel designed a survey instrument to measure and compare healthcare services known as the HCAHPS [66]. The strategy for management using HCAHPS survey is to improve patient satisfaction and healthcare services [66]. Leaders with the Centers for Medicare and Medicaid services (CMS) created the Hospital Value-Based Purchasing (VBP) program with HCAHPS as one of the components [67]. The VBP program tied to a Total Performance Score (TPS) comprises of two areas, a clinical process of care, and a patient experience of care [68]. The clinical process of care is $70 \%$ of the TPS, and the HCAHPS is $30 \%$ of the TPS. The purpose of the HCAHPS instrument is to measure patient perspectives of hospital care and make valid comparisons across all hospitals to support consumer choice [68]. Consumer satisfaction in healthcare is necessary for organizational leaders to meet goals, obtain revenue, and stay competitive in the healthcare market [69] [70].

\section{Research Method and Design}

\section{Research Method}

The study was a qualitative exploratory single case study to explore the strategies hospital managers use to improve customer service. The research study was to compile data in the real-world context from hospital managers regarding customer service strategies. Sinkovics and Alfoldi (2012) [71] indicated that qualitative researchers formulate open-ended questions; however, additional questions may emerge throughout the research study. The flexibility is essential to probing the subjects and asking for additional information to explore what the participant is saying [72]. The hospital managers revealed the strategies they use for customer service and how these strategies affect customer service in hospitals. The intent was to retrieve in-depth information from the participants through semistructured interviews, and probing the participant for additional input on the strategies of customer service.

\section{Research Design}

The study included a single exploratory case study. Single case study research is necessary when the intent is to obtain an up-close and in-depth understanding of an individual case [73]. Yin (2014) [73] described case study researchers as focusing on the integrity and wholeness of a case within the cases real world context leading to an understanding of the case. The case study revealed up-close and in-depth information regarding the strategies that hospital manager's use to improve customer service strategies improving customer satisfaction. 
Case study research is useful when studying organizations to ask what, how, and why questions regarding events that the researcher has no control [74] [75]. A connection must exist between the case study participants and the case. In an exploratory case study, the intent is to explore the research question to determine the nature of the issue and to receive a better understanding of the problem [76]. Through the case study research design, elements came from a healthcare managers' perspective that help hospital employees perform satisfactory customer services.

\section{Population and Sampling}

The study included hospital managers from a hospital system in Nevada. The criteria for the research study were hospital managers who implement customer service strategies. Purposive sampling was the sampling method for this research study. Barratt, Ferris, and Lenton (2015) [77] indicated that researchers use purposive sampling to gain insight and discover a better understanding of the phenomenon. The interviews came from hospital managers who were insightful of the customer service strategies they implement at the hospital. In addition, interviews came from Face-to-face and phone interviews through telephone contact then email. Phone interviews were an option for participants who requested to meet by phone because of time conflicts with work or their personal life. Although coffee shops and restaurants are convenient locations, they are usually noisy places [78].

\section{Data Collection Instrument}

The researcher is the instrument for the study. Audio recording of the semistructured interviews occurred and the responses of the hospital managers. As an essential instrument in research, Hansman (2015) [79] described that researchers must remain aware of potential bias throughout the research study and put all personal assumptions aside. The data sources included interview responses, documents of hospital policy and procedures, and HCAHPS qualitative data from the Hospital Compare website. The goal of using semistructured interviews was to create an environment where the participants can provide a comprehensive understanding of their ideas and meanings [80]. The interview questions for the hospital managers generated answers that described strategies of customer service that contribute to customer satisfaction.

\section{Data Collection Technique}

In the data collection, process was to schedule interviews with the study participants through telephone contact. The participants had the opportunity to accept or decline the interview invitation. Emailing consent forms were necessary after scheduling the interview. When sending a copy of the consent form, the participants must have the option to read the consent form in-depth and ask any questions before signing the consent to participate [81]. Interview participants received a copy of the signed consent forms at the interview location. The interview took place in a quiet meeting room. After completion of the interviews, transcribing the interviews and protocol notes into file documents occurred. 
The following day after the initial interview, contacting the participants by phone occurred for member checking. The participants verified the data and elaborated further on the meaning of their responses, which provided new and in-depth consisting of reviewing and recording the HCAHPS hospital survey qualitative data of patient experiences from the Hospital Compare website. The importance of the research study reflects in comparing the HCAHPS scores to the data from the interviews, policy and procedure documents, interview protocol notes, and the transcribe notes.

\section{Data Organization Techniques}

The data collected will remain in a locked file cabinet in an electronic folder on a flash drive. Locking the data away ensures the data is secure and not retrievable by anyone else. The folder for the data, named customer service research, has five sub-folders inside. Each sub-folder relates to the participant's participation in the study and the participant status. For example, the hospital manager who participated in the interview first labels as HM1. The proceeding hospital managers labeled from HM2 - HM5. Interview data, member checking data, interview protocols, and transcribe notes are filed in the participant folder. Using labels or codes is to protect each participant's confidentiality [82]. Vohra (2014) [83] used codes and labels to organize the data, explore patterns, and generate themes before data analysis. The labeling of participants is to eliminate the need to record names, titles, and workplace. One sub-folder labeled notes consists of the data retrieved from the HCAHPS hospital compare website and hospital documents of policy and procedure received from hospital website.

Organizing the data from the interviews by the number associated with the interview questions was necessary. The interview questions received coding by themes, keywords, and descriptions to capture the data with little interpretation. The codes make establishing patterns of each interview response easier [84]. The interviews received transcription word for word onto a word document and posted to a Pdf file labelled by the participant for example, HM1 - HM5. The notes from the interview will go into a word document using the same user codes HM1 - HM5. Other data for example, hospital manager's documents, including policy and procedures, and information received from the HCAHPS received scanning and stored in a file labeled HMD and HCAHPS.

\section{Date Analysis}

The data for the study came from methodological triangulation from one-on-one interviews, hospital policy and procedure documents, and data from the HCAHPS hospital compare website. To generate standard themes, transcribing and coding all the data from participant interviews and member-checking follow up interviews occurred. Documents of policy and procedures, and the hospital systems results from the HCAHPS hospital compare website to gain an understanding. Searching for meaning and triangulating the key concepts and ideas from the interviews, policy and procedure documents, and HCAHPS data from the hospital compare website to transfer the data into 
the NVivo $10^{\circledR}$ data analysis software. NVivo $10^{\circledR}$ qualitative data analysis software is the software I used to analyze the data.

After each interview, transcribing participant interviews and conducting the member checking occurred the next day. Interview transcription, hospital policy and procedure documents, and HCAHPS data from the hospital compare website went into NVivo $10^{\circledR}$. Coding is categorizing and grouping the data so themes can emerge [84]. Comparing and coding the data applied in identifying major themes and patterns in the participant responses, hospital policy and procedure documents, and the HCAHPS qualitative data was necessary. To generate the major themes, reading all the concepts and ideas from all the data and searching for relationships, the same network of ideas, and repetitive key words was necessary. Grouping the data into nodes by major themes and patterns included core themes from performing several frequency queries and text search queries in Nvivo. The themes generated were all new themes and had similarities and differences from the themes in the literature review. The results revealed in this study maintain the conceptual framework of the study.

\section{Reliability and Validity}

Reliability and validity are research requirements to ensure the results of the study are valid and credible [85]. Sinkovics and Alfoldi (2012) [71] argued that there be no definite place in qualitative research for reliability and validity because neither is directly applicable to qualitative research. To enhance creditability, required using methodological triangulation, examining notes from the interviews, and member checking follow-up interviews, hospital policy and procedure documents, and the results from the HCAHPS hospital survey analysis.

Ensuring credibility required using hospital policy and procedure documents, hospital manager notes on strategies, and data from the HCAHPS hospital survey website. Member checking is another important method to ensure dependability and credibility in qualitative research studies [86]. To ensure accuracy in the interpretation of the participant interview, participant feedback was necessary. Cope (2014) [87] suggested Member checking is appropriate after data analysis to ensure reporting of participant data is correct. Member checking is an opportunity for participants to verify the interpretation of their answers [33].

Confirmability mitigates bias in the data. The use of confirmability is the process of data received and recorded from the responses of the participants [87]. Investigators use an audit trail consisting of interview protocols, notes, and research materials to maintain confirmability [71].

\section{Findings}

The findings reveal that exploring employee training relate to the conceptual framework of the expectation-confirmation theory. The participants described multiple attempts to alter operations within the hospital based on customer expectations for satisfaction and to confirm customer satisfaction for the hospital system. Joo et al. (2017) [1] used the expectation-confirmation theory to verify 
that customer expectations have a major role in linking the customer to satisfaction and loyalty. Hospital managers performed actions for example, hiring the right people, using customer feedback for improvement, and using the HCAHPS qualitative data to create strategies that would meet customer expectations for satisfaction and loyalty.

To develop the primary research question further, semistructured interviews and member checking interviews to obtain the strategies hospital manager's use for customer service were necessary. Reviewing of hospital policy and procedures documents occurred. Qualitative hospital data from the Hospital Compare website to triangulate and analyze the key concepts and ideas from the participant's interview data occurred.

The conceptual framework for the study was the expectation confirmation theory. The expectation-confirmation theory includes ideas of concepts of expectation, performance, confirmation, satisfaction, and repurchase intentions [20]. The expectation confirmation theory was appropriate to explore the strategies hospital managers use for successful customer service in hospitals. The expectation-confirmation theory was useful in aligning the reasons why, what, and how, customer service strategies help hospital leaders improve customer service.

\section{Emergent Theme 1: Interpersonal Communication}

A major theme to answer the research question of what strategies do hospital managers use to improve customer service was interpersonal communication. Interpersonal communication is a form of communication where people communicate face to face using verbal and nonverbal exchanges of information, emotions, and feelings (Sarapaivanich \& Patterson, 2015).

The concept of communication occurred throughout the hospital manager interviews, documentation in the hospital policy and procedure manual, and evaluated on the HCAHPS hospital compare website. Sam (Pseudonym) stated communication is the one method that ties all the strategies together toward patient satisfaction. Verbal communication is important to have with patients to learn patient needs and how to help patients. Verbal communication is important for hospital managers with hospital staff to ensure the necessary tools are used to take care of the patients. Grill, Ahlborg Jr., and Wikstrom (2014) [88] conducted a qualitative study where eight healthcare managers participated in the interviews. The eight healthcare managers verified that managers in healthcare should promote interpersonal communication within their hospital because managers communicating with staff provide a quality work life for hospital staff. Grill et al. (2014) [88] findings align with the results to the findings that interpersonal communication is an important aspect to ensure good customer service within hospitals.

Judy (pseudonym) stated communication with the patient is what encourages customer feedback because the patient or family member feels comfortable talking about any issues or any concerns. Linda (pseudonym) stated communication with staff helps the manager reinforce the need for a satisfying patient expe- 
rience. A manager communicating patient needs to staff members on a regular basis is necessary to ensure the staff buy in and feel a sense of organizational commitment. A study conducted by Hsu et al. (2011) [89] on nurse communication aligned with the opinion of Linda's statement indicating communication with nurses encourage nurse commitment to the organization and an excellent patient experience. Hsu et al. (2011) [89] found that stimulating interpersonal communication help managers pursue organizational commitment with a higher level of customer satisfaction. Linda verified that Hsu et al.'s [89] findings 6 years ago remain true because patient satisfaction continues to increase with hospital manager communication of patient needs to staff and nurses within the hospital system.

John (pseudonym) referred to communication as the way to address individual needs. John stated, Communication with staff is important to make sure they understand the empathetic and caring approach that we want to establish when caring for our patients. We also must communicate with the patient to make sure we know exactly what type of environment to create for each patient's comfort.

As referenced in the hospital policy and procedure manual, one of the missions of the hospital is to provide spiritual care that mends the mental and physical body and heals the soul. Jan (pseudonym) referenced communication beginning the minute the patient enters the hospital until months after the patient discharge. Jan stated communication is about listening to the patient and family members and addressing their needs and wants throughout the hospital stay. When a patient receives discharge notification, communication continues by telephone calls directly to the patient to make sure the patient is feeling well and had a good hospital stay.

Participant responses, policy and procedure documents, HCAHPS data, the literature review, and current research included several strategies hospital managers used for customer service. When the major theme of interpersonal communication emerged from participant interviews and the hospital policy and procedure documents, several core themes developed. The core theme of leadership rounding, recovery, and reinforcing surfaced while discussing interpersonal communication through interviews and the policy and procedure documents. Interpersonal communication is important to improve customer service in hospitals.

Leadership Rounding. Participant interview responses and the hospital policy and procedure documents showed leadership rounding was an important strategy in customer service. All five participants identified the core strategy of leadership rounding to improve customer service for patients in the hospital. Leadership rounding is a concept used for helping workers achieve their best, increasing trust levels between staff and management, improving operations, connecting with patients, and reducing errors (Blair, 2014) [90].

Linda referred to leadership rounding as a process improvement protocol for 
both patients and hospital staff. Leadership rounding is when top leaders for example, Directors, Vice Presidents, and the Chief Executive Officer visit with patients who are admitted to the hospital or emergency room. During these visits, leaders tend to patient care as well as talk with the patients to make sure the patient is having a satisfactory experience. John and Jan described leadership rounding as a strategy that leaders use to visit with staff and get to know them. Jan referred to the strategy that patients come second and employees come first. Leaders must ensure the happiness of staff so staff can deliver excellent customer service to patients. John related rounding to employee engagement. When employees believe that managers care about them, then employees will start to engage with the patients and make sure the patients have an excellent patient experience. Engaged employees will focus on the goals of the organization. Leaders start the practice of engagement and employees will then buy-in and become engage. Linda indicated the elbow-to-elbow interaction with staff helps leaders reinforce the customer service strategy and helps front line staff deliver quality customer service. Sam and Judy related leadership rounding to bringing up moral for front line staff. Judy stated when leaders work side by side with front line staff, it gives the staff a sense of pride and appreciation, and it inspires the employee to want to do better.

Rijal (2016) [50] discovered that organizational leaders have a major role in creating a positive environment for employee engagement and customer satisfaction. In the hospital policy and procedure manual, one of the missions of the hospital organization is to collaborate with others and the community to improve the quality of care and life. Rounding is the process of organizational leaders collaborating with front line staff and patients to ensure excellent customer service to both staff and patients. John stated, "Rounding helps improve the internal customer experience to promote employee engagement and improve the external patient experience to promote patient satisfaction." In a service organization, the customer-oriented approach is when leaders create value for both the internal and external customer [91].

Three hospital managers shared that leadership rounding is the strategy that worked the best for improving customer service for both staff and patients. Sam reported the visibility of the leaders gives both the patients and staff a sense of genuineness. Judy said the effectiveness of the leadership rounding puts a face to a name and makes the hospital more down to earth for patients and staff. Linda stated leadership rounding is best at improving customer service because it provides the leader an opportunity to talk with patients and staff and smooth out any discrepancies before they occur. Rounding is especially helpful to ensure good scores on the HCAHPS surveys and reimbursement payments from CMS. The five hospital managers mentioned leadership rounding as being one of the most important strategies to ensure communication for patients and staff and to ensure customer satisfaction. Judy reported that sometimes the difficulty arose with leadership finding the time to perform the leadership rounding. Leaders 
must take time out of their busy day to wait on patients, talk to staff and patients, and just be visible within the hospital system. Blair (2014) [90] confirmed that leadership rounding is one of the most effective ways to communicate with patients and ensure patient satisfaction in a healthcare system. Hospital managers have difficulty providing good customer service when there is a lack of communication with patients. All hospital managers agreed that leadership rounding helps meet the expectations of both the internal and external customer to ensure customer satisfaction. Leadership rounding is important for hospital managers to ensure good communication and a good customer service experience for the patient.

Recovery. Data from participant responses, the policy and procedure documents, and the hospital compare website confirmed recovery as a core theme. Linda described service recovery as employees having the ability to resolve issues as they transpire by hearing, empathizing, apologizing, responding, and thanking the patient for bringing the issue to their attention. As documented in the hospital policy and procedure manual, the acronym for this type of care is HEART. Linda stated, HEART care is an initiative for service recovery to ensure an excellent customer service experience. The hospital value statement entails respecting the value and worth of others, exceeding expectations through teamwork, and using many resources to promote healing. Sam mentioned recovery as an opportunity to correct immediately any wrong or ill feelings from the patient before the problem becomes an issue that is not correctable. Judy asserted that recovery is about the customer service philosophy of meeting customer expectations. The idea of the expectation-confirmation theory is customer expectations determine customer satisfaction [20]. The importance of recovery is communicating and addressing patient issues from the beginning of the hospital stay so issues are resolved and the patient can have a satisfactory experience. The patient will let others know of their satisfactory experience and the hospital will gain loyal patients, acquire a caring reputation, and attract new patients.

Although, John and Jan stated service recovery was a major form of communication helping managers gain insight on customer expectations and needs. Jan stated recovery was one of the factors that help increase satisfactory ratings on the hospital compare website for communication. The hospital compare website includes a rating of $71 \%$ in satisfactory communication for the hospital system. The hospital compare website reports the national average of satisfaction is $80 \%$ and Nevada's average is $73 \%$ for all hospital systems. Jan believes hospital managers are on target with improving customer satisfaction through communication. Recovery is an important strategy for hospital managers to improve customer service and customer satisfaction.

Reinforcing. The hospital managers addressed a few challenges when implementing customer service strategies into the daily operations of the hospital. Reinforcing is a core theme and a challenging strategy set forth by all 5-hospital managers. Sam and Judy stated the challenges faced when implementing customer service strategies was getting the staff to accept the changes and imple- 
ment them. Linda, John, and Jan addressed the challenge of changing staff mentality. Linda referred to the challenge as difficulty changing hearts and minds of the staff. People who believe that taking care of the patient only involves the physical aspect, it can be a challenge changing the way people think and changing the way they feel in their heart. That is why it is important to collaborate with staff and provide them with support. People must be committed to the work they do.

To address challenges all hospital managers stated the importance of having conversations to educate staff on the importance and the reasons why customer service is important in healthcare. Judy stated the necessity for long and lengthy conversations with staff to reinforce what needed to happen and why it needed to happen. Linda referred to transparency and long conversations with staff that would sometimes generate self-reinforcement strategies that were useful in overcoming the challenges. For example, one staff member put post notes on her desk reminding her to smile every time she greeted a patient or patient family member. John stated the conversations must begin at hiring and continue throughout the months and years of employment. Employee emotional performance is important when interacting with customers [92]. John stated, the only way to make sure your employees are onboard is to continuously talk to them and find out exactly where they are mentally and emotionally. A person cannot deliver quality service if they do not believe in what they are doing. As a leader, I must reinforce making sure my employees believe in what they are doing and actually want to do it.

The analysis through participant interviews, hospital policy and procedure documents, and qualitative HCAHPS data from the hospital compare website indicate interpersonal communication is critical in improving customer service in hospitals. Leadership rounding, recovery, and reinforcing are forms of interpersonal communication that relate to the conceptual framework the expectation-confirmation theory. The participants revealed strategies that support customer expectations of satisfaction and support confirmation of customer satisfaction within the hospital system.

Tahir et al. (2013) [24] conducted a study using existing research in psychology and marketing to show the strong relationship between customer expectations and satisfaction.

Tahir et al. (2013) [24] used the expectation confirmation theory to confirm that when customer expectations are successful, satisfactions confirmed. Hospital managers use strategies of leadership rounding, recovery, and reinforcement to ensure successful interpersonal communication with hospital staff and patients to confirm satisfaction. Through interpersonal communication, hospital managers can reveal customer expectations and confirm or disconfirm customer satisfaction.

\section{Emergent Theme 2: Hospital Environment}

Hospital environment was the second major theme that emerged to answer the research question of what strategies do hospital managers use to improve 
customer service. Three core themes emerged from hospital environment. The three core themes were physical environment, company culture, and patient experience.

When the major theme of hospital environment emerged from participant interviews, hospital policy and procedure documents, and HCAHPS data from the hospital compare website several core themes materialized. The core themes materialized from identified patterns in participant interviews and hospital policy and procedure documents and comparing the themes to qualitative data on the HCAHPS hospital compare website. The core themes of physical environment, company culture, and patient experience emerged when exploring the hospital environment. The results of the information confirm that the hospital environment is a major aspect to improve customer service in hospitals.

Physical Environment. Participant interview responses and policy and procedure documents confirmed previous research findings that physical environment of the hospital is important for the mental and physical well-being of the patient. Jan recognized that maintaining a clean, neat, and calm environment is a strategy that is non-negotiable in a hospital setting. Patients are in the hospital because of need, not want. Improving the physical environment and making sure the patient stay is nice and comfortable is a big part of the healing process and provides a satisfying patient experience. Hospital policy and procedure stated the patient has the right to receive considerate, respectful, and comfortable care. Judy and John discussed room service available for patients to order from a custom menu and the cafeteria cook will prepare the meal specifically to the patient specifications. Judy stated that a neat and quiet hospital environment not only provided good customer service to the patients but also provided a satisfying work environment for hospital staff. Linda stated that free Wi-Fi service is another strategy used so patients and family members can browse the internet or access emails for their entertainment and comfort. However, Judy said Wi-Fi would be the least effective strategy of customer service because Wi-Fi is not a major part of customer service. Sam referenced the call light where patients and family members can hit a button and hospital staff will respond to their needs within seconds. Maintaining a clean and satisfying hospital environment is an important strategy to ensure satisfactory customer service for both the internal and external customer. Data retrieved from the hospital compare website displayed an above average rating nationally for the hospital system in hospital cleanliness; however, for hospital quietness, the hospital system rates slightly below the national average for satisfactory [93].

Company Culture. Participant interview responses and the policy and procedure manual showed hospital leaders promoted a positive company culture as a core strategy for customer service. Organizational leaders establish and promote company culture through organizational goals [50]. An organizational goal from the policy and procedure manual for the hospital staff is appropriate to create a culture of spiritual care for both internal and external customers. Hos- 
pital leaders created a culture of spiritual care by promoting transparency with staff, volunteers, and the leaders themselves. Liu et al. (2013) [51] verified that employees perform beyond expectations when organizational decision makers promote a culture of transparency. One of the values hospital leaders discussed from the policy and procedures manual of the company culture created by hospital leaders is to respect the value and self-worth of each person. Jan stated, employees come first within the hospital system and patients come next. Jan shared the notion that if employees are satisfied, employees will treat the patients well. Linda described a culture where staff and volunteers spend time with the patients and families getting to know something special about each patient to personalize the patient experience. For example, if a patient expresses an interest in a movie, hospital staff will make sure to play that movie in the patient hospital room to ensure patient satisfaction. Sam and Judy created a culture where people can be genuine in their feelings and treat everyone the way he or she wants to be treated.

To motivate employees and establish the company culture, several strategies existed. First, many employees are already motivated. Judy stated most people who work in hospitals already have the helping nature. Motivating staff to improve customer service can take several measures. Employee awards and recognition, storytelling, empowerment, retreats, celebrating acts of kindness, and treating people the way you would want to be treated.

Sam's way of motivating staff is to treat people with dignity and respect. Judy referred to motivating employees by communicating with them and being transparent as to why customer service is so important. Linda related motivation to recognizing employees who provide exceptional service and celebrating their accomplishments through awards and recognition. Celebrating employee successes with other employees will motivate other employees to do a good job. For example, if an employee gets a customer praise letter for providing good service, hospital leaders will recognize that employee in a staff meeting and ask that employee to share their positive experience. John supports the idea of having retreats and training to educate and motivate staff on customer service tactics and skills. Jan related motivation to awards and recognition. Recognizing the employee by providing appreciation pins that the employee can wear on their work uniform and celebrating with a cake is appropriate to recognize outstanding employee service. Successful employees tell their stories to everyone, and other employees see the rewards and recognitions given out which motivates employees to want recognition and win awards. [57] conducted a qualitative study on employee commitment and patient satisfaction where they interviewed fifty employees from two different healthcare centers. Murale et al. [57] found that organizational leaders who create a satisfying company culture have better employee commitment, values, and customer service. Murale et al.'s [57] study aligns with the results to the findings that organizational leaders who create a satisfying company culture have better employee commitment, values, and cus- 
tomer service.

Patient Experience. The hospital policy and procedure documents, qualitative data on the hospital compare website, and the responses from the participant interviews confirm that the patient experience is a major aspect of customer service strategies. The HCAHPS patient experiences survey is appropriate to use for reporting patient satisfaction or dissatisfaction with their hospital visit. $\mathrm{Pa}$ tient experience ratings range from $0-10$ with 0 as the lowest rating and 10 as the highest rating. Patients who took the patient experience survey and gave the hospital system a rating of 9 or 10 on the hospital compare website was $71 \%$. The Nevada average for patients who gave their hospitals a 9 or 10 rating was $65 \%$ and the National average was $72 \%$. The results of this data demonstrated that the hospital system is right at the national average and leading other Nevada hospital systems in patient experience satisfaction.

All participants identified a positive affect from the strategies used to deliver quality customer service to patients. Hospital staff using all the strategies identified can drive excellent customer service ensuring the delivery of a better patient experience. In the hospital policy and procedure documents a mission of the hospital is transparency with patients and family members to ensure a high quality of service and a satisfying patient experience. Sam stated patients and family members are involved in the decision-making process of patient care. Customer service strategies help staff deliver messages and explain things more effective. Patients and families have a better understanding of a patient situation and have the support needed to work through situations. Rangachari et al. (2011) [65] explored organization leaders' ability to create a customer-oriented approach in healthcare and found that creating a satisfying patient experience included patient involvement in the decision-making process of patient care. The results of Rangachari et al.'s [65] exploration relate to the findings because hospital managers stated that patient involvement in care decisions help create a satisfying patient experience. Sam, John, and Jan emphasized that patients are in the hospital not by choice but because of an illness and a need for care so a positive patient experience is required to help them heal. Healthcare is an adverse service because hospital visits are usually stressful and physically unpleasant [2]. Customer service strategies help in the healing process because patients need more than the physical care they need emotional support and kindness. Judy stressed that customer service strategies affect the hospital environment in a positive light and help staff provide an overall satisfying patient experience. Hospital staff should have the social skills, personality, and right attitude to carry out the hospitals mission for a satisfactory patient experience.

Linda used customer service strategies for example; leadership rounding to get to know patients and make sure their hospital stay exceed their expectations. A positive patient experience is about creating an environment where the patient feels at home. Feeling at home is calling hospital staff by name and feeling comfortable talking to staff because staff has already created that personal feeling. Jan 
stated challenges in creating a positive patient experience is getting some staff to see that healing is more than saving lives, it is about providing human kindness and making people feel good.

Based on the analysis from the interviews, hospital policy and procedures documents, and the qualitative data from the HCAHPS hospital compare website on hospital environment, the core themes for hospital environment relate to the conceptual framework of the expectation-confirmation theory. The patient experience, company culture, and the physical environment of the hospital connect to the expectations of the patients. The expectation-confirmation theory framework includes satisfied or dissatisfied customers based on the customers' subjective expectations [94]. From the perspective of the hospital managers, patient expectations for satisfaction are the key drivers of the strategies for patient experience, company culture, and the physical environment of the hospital.

\section{Emergent Theme 3: Employee Training}

Four of the five hospital managers described employee training as another major strategy that hospitals managers use to improve customer service. Jan stated, "We do not ask staff to do anything that we do not provide training. We train our employees. That is our responsibility as leaders." Three of the hospital managers referred to training as a major part of the hiring process. Jan stated that not everyone is capable of training; therefore, the importance of training aligns in the hiring process. The importance relies on the ability of the leader to hire the right person with the right personality and social skills so he or she is capable of learning through training. Judy and John described a big part of training as creating patient experience committees with employees who work together to identify the current situation of the strategies and use brainstorming to enhance and improve the strategies for customer service. New employee training, patient feedback, and HCAHPS scores are core themes that emerged from the strategies that relate to training. These themes emerged from the hospital manager interviews and information retrieved from the hospital policy and procedure documents. The hospital policy and procedure documents include new hire in the training section to fulfill the vision of excellence that hospital leaders promote. The expectations of hospital leaders are for staff to receive ongoing training, collaborate through teamwork, and learn innovation. Hiring and new employee training is part of the training process because when new people are hired, their status are trainees for at least 6 months before they become a hospital employee. The hospital leadership team views hiring as part of the training process. The person chosen for the job must prove that they are trainable before they are officially hired which can take up to six months of training in the hiring process.

When the major theme of employee training emerged from the participant interviews, hospital policy and procedure documents, and HCAHPS data from the hospital compare website several core themes emerged. The core themes of new employee training, feedback, and HCAHPS emerged when exploring em- 
ployee training. As written in the hospital policy and procedure documents, training is a requirement of all new hire trainees and all employees must register for 8 hours of training quarterly. Linda responded that it is mandatory for hospital leaders to make available training opportunities for employees and educate staff on why customer service is so important. Jan suggested that leaders must reinforce the need for consistency in delivering an excellent patient experience allowing staff to learn through role-play and skill labs set up in the hospital. Vogus and McClelland (2016) [70] interviewed prominent hospital leaders from 269 non-federal acute care hospitals in the United States. Vogus and Mclelland [70] found that hospital employee's ability to interact and engage with patients in a positive manner is necessary for the success of the overall patient experience. Likewise, the findings showed that when hospital employees engaged positively with patients, the patients reported a higher percentage of satisfaction on the HCAHPS survey. Sam reported the difficulty of training and making the strategies uniform in each hospital within the system because of the different managers and staff at each hospital. The different personality and perspectives of each manager can include a role in the delivery and teaching of the customer service strategy to individual staff.

New employee training. John described the hiring process as a crucial customer service strategy that hospitals must get better. Hiring people for fit and training for skill. People who apply to work in a hospital should already have a positive personality and skills for example, empathy, caring nature, smiles, and human kindness. Handa and Gulati (2014) [4] verified through research that a positive personality is an important role for individual success in an occupation. John and Jan reported that hiring the right people is the customer service strategy that works the best because employees help build the reputation of the hospital. Jan stated that employees must get through months of new employee training before their probationary period is over and they are offered a permanent status as an employee. John stated if you do not have the right people with good attitudes, none of the training that you implement works. Jan reported that hiring the right people is the key to motivating everyone to work as a team. Teamwork is essential to providing an excellent patient experience.

John and Jan related the least effective customer service strategy to hiring the wrong people and those people not being able to fulfill the goals and mission of the hospital. Jan stated that accountability is a major factor in customer service. If managers do not hold their staff accountable to deliver, the strategies that are set forth, that would be the least effective strategy. The mission of the hospital is commitment to furthering the healing ministry by delivering high quality and compassionate care. People hired must have a positive attitude so the training they receive will become a part of their daily interactions with patients. Sam asserted that training is an ongoing process. Training starts with the hiring of the right people and continues throughout the employee employment at the hospital.

Feedback. Sam and Linda referred to customer complaints as concerns rather 
than complaints. Sam stated that hospital staff should view complaints as concerns. When hospital staff view concerns as complaints, many time the staff feel like the patient is upset with them rather than angry about the problem. When hospital staff receive complaints as concerns then that's just what it is, a concern, it is nothing personal. A patient never complains, the patient is rather just voicing a concern so hospital staff is aware and can take care of the problem right away.

Linda stated customer concerns provide valuable information and feedback that hospital managers can use when brainstorming solutions and creating training sessions for employees. John believes that every customer or patient who takes time to provide feedback should receive a telephone call to ensure no misinterpretation of the feedback and the interpretation of the feedback is valid. Judy referred to patient feedback from hospital surveys that patients receive 2 days after discharge. Hospital leaders ask for patient feedback before the patients receive the HCAHPS surveys. Receiving patient feedback before the patient receives the HCAHPS survey gives hospital managers an opportunity to contact the patient and smooth out any discrepancy. The importance relies on the patient giving the hospital a high rating on the HCAHPS so the hospitals satisfaction rate will increase. The hospital managers review the patient feedback. The hospital managers implement the feedback through customer satisfaction trainings and role-play activities. Jan created trainings for hospital staff on patient experience and customer service. Jan stated that over $85 \%$ of employee, created training was in response to customer feedback from hospital surveys, and complaints received from patients during leadership rounding and hospital staff visits with patients. Linda stated that several of the hospital staff assisted in creating and implementing changes for customer satisfaction based on negative customer feedback. Jan reported that she shares customer feedback with staff because many times the staff do not realize they are making mistakes and are quick to want to correct the mistakes.

One of the values set forth by hospital organizational leaders promotes respect, transparency, and compassion for brothers and sisters who are powerless. To stay in compliance with hospital values from the policy and procedure documents, Jan stated the importance of making sure the patients and customers have a voice. Listening to patients, accepting their feedback and complaints, and making changes to ensure the patient voices heard. Customer feedback is a major part of the training process for employees. Customer feedback provides managers with valuable information to implement changes for satisfactory customer service and satisfaction through training and activities.

HCAHPS. Hospital managers had the opportunity to discuss additional information that improved customer satisfaction. Hospital policy and procedure, and the qualitative data from the hospital compare website helped verify participant responses that HCAHPS scores was an important factor in the implementation of customer service strategies in hospitals. Jan stated the goal of creating 
an exceptional patient experience had been a mission of the hospital system for years, before the HCAHPS surveys and before CMS reimbursements. The HCAHPS survey came from the leaders from the Centers for Medicare and Medicaid Services (CMS) and the Hospital Value-Based Purchasing (VBP) program to measure patient perspectives of hospital care to make comparisons of all hospitals for consumer choice [67]. However, all other hospital managers suggested the entire customer service initiative to improve customer satisfaction in hospitals was in response to the HCAHPS survey scores.

Patients receive HCAHPS surveys 48 hours to 6 weeks after discharge from the hospital. Linda reported HCAHPS is important because hospitals receive reimbursements from CMS based on these HCAHPS scores. The higher the score, the more reimbursement, and revenue the hospital will receive. Judy stated HCAHPS measures patient perspectives on hospital care and rates the hospital based on a state average and a national average using a 5-point start system. Those ratings are how CMS pays or penalizes the hospital for a positive or not so positive patient experience. Sam and Jan reported the hospital is currently working on raising HCAHPS scores and would like to be above national average. John stated these strategies are just the beginning of what the hospital is doing to raise the HCAHPS scores and become a choice for patients in healthcare. John stated, "We are currently at the $50 \%$ level for satisfaction, and we want to be above $75 \%$ therefore, we are working hard at implementing these strategies for success."

The purpose of the HCAHPS survey is for leaders of Medicaid and Medicare to measure patient perspectives of hospital care and services and make comparisons of hospitals to support consumer choice [67]. In viewing the qualitative HCAHPS data from the Hospital Compare website, the hospital system scored below the national average in patient experience. A pattern occurred in the generated themes for strategies that hospital managers use for customer service and the categories measured on the HCAHPS survey. The measured categories on the HCAHPS survey are different types of communication, cleanliness, and quietness of the hospital environment, the responsiveness of staff, and care transitions. The themes that emerged from the hospital manager strategies of customer service relate to the patient questions on the HCAHPS survey. Jan asserted HCAHPS survey scores reported on the hospital compare website provided data hospital managers need to implement or change trainings of customer service and customer satisfaction.

In summary, a need exists for additional research regarding hospital and healthcare manager's strategies for customer service. As indicated by Itumalla (2012) [64], previously hospitals received ratings by the quality of medical services provided and now hospitals realize patients want quality service as well. The participants in the study indicated that hospitals now receive ratings not only based on the quality of medical services provided but also on the quality of customer service provided to patients. The hospital manager's responses, hospit- 
al policy and procedure, and the HCAHPS data from the hospital compare website verified several effective business practices in the literature review. Several new studies emerged regarding customer service and healthcare. In response to the HCAHPS scores and their importance to hospital leaders, many new studies emerged regarding customer service and customer satisfaction in healthcare. All five-hospital managers suggested that all strategies are necessary and work hand in hand in providing a satisfactory patient experience.

\section{Applications to Professional Practice}

The results of the study revealed several strategies for delivering customer service to internal and external patients in healthcare and providing a satisfying patient experience. The findings from the study may help current and new healthcare decision makers develop customer service strategies that could lead to customer satisfaction and loyalty in healthcare. The hospital managers who participated in this study were hospital decision makers who create strategies of customer service in hopes of providing a better patient experience and increasing HCAHPS scores. Current and new healthcare managers may consider these strategies useful in the day-to-day operations of the hospital, clinic, doctors' office, or any business in healthcare that serves patients. The findings from this study proved the customer service strategies were successful for the participants. The Hospital Compare website reveals an increase in satisfactory HCAHPS scores for the hospital system. Customers are reporting satisfaction on their HCAHPS surveys.

The support of decision makers from leadership rounding can provide other healthcare leaders knowledge to improve business operations and maintain a loyal customer base. The information collected from this study can lead to improved customer service and experiences in healthcare from healthcare decision makers recalling the importance of excellent customer service. Healthcare decision makers may want to remember that healthcare customers are demanding a better customer service experience when spending their money [7]. The revealed customer service strategies can help healthcare decision makers expand their business, customer base, and become leaders in customer satisfaction. For example, training staff to provide excellent customer service may lead to customer satisfaction and customers returning for services.

\section{Implications for Social Change}

The results of the study are an important factor to the increasing interest in the literature relating to customer service in healthcare. Healthcare is consistently growing and becoming more of a competitive business [17]. The findings from the study revealed that customer service strategies could help healthcare leaders improve the quality of customer service and the patient experience. The healing process for patients requires both physical and emotional care. Hospital managers who have successful strategies for customer service can share these strategies with other healthcare leaders. Sharing the findings from the strategies of customer service used by hospital managers can help improve the healthcare 
environment, quality of service and care, and the healing process for patients. Hospital leaders can increase Hospital Consumer Assessment of Healthcare Providers and Systems survey scores and reimbursement from Centers for Medicare and Medicaid Services, which generates more revenue for the hospital system. More revenue in the hospital system leads to additional funding to improve healthcare and the quality of life within the communities.

\section{Recommendations for Action}

The results of this study are relevant to any healthcare professional or organizational groups who want to develop and enhance their skills in customer service and patient satisfaction. Leaders and stakeholders in hospitals, medical clinics, doctor offices, and nursing homes can use the results of this study to generate ideas to create their strategies for customer service to improve customer satisfaction. Healthcare professionals for example, nurses, physicians, therapist, clinicians, and administrative staff, who may not have effective customer service strategies, or who are starting out in the healthcare industry, can acquire a stronger understanding of the expectations to ensure a satisfying customer experience. Leaders of Centers for Medicaid \& Medicare Services who incorporate the HCAHPS survey could use the results to gain insight on the measures, lengthens, and changes that hospital decision makers are using to promote a positive patient experience. Customers in healthcare, as well as the public, can review the results of this study to understand the difference between patient care and customer service. Customers who understand the difference between patient care and customer service should answer the HCAHPS survey effectively. Customers answering the HCAHPS survey effectively will provide a more accurate rating for the hospital.

The type of customer service experience a customer has depends on the customer expectations and the interactions with staff [95]. The strategies identified in this study relates to the interactions with customers and expectations of service providers. The results of this study can prove helpful for leaders to train staff on interacting with customers and meeting customer expectations.

\section{Recommendations for Further Research}

Further research can include other hospitals or healthcare systems. Healthcare is broad, and the study has limitations to only one hospital system in Nevada. A comparison of two hospital systems could prove helpful for healthcare leaders to determine the similarities and difference in the strategies used. Focusing on different populations for example, veteran hospital systems or military hospital systems could reveal strategies. Exploring the difference in customer service strategies at for-profit hospitals versus charity hospitals could show different strategies. Future research should include exploring nursing home strategies, and how effective the strategies work for customer service.

Future research could include the perceptions of patients and customers in healthcare on the effectiveness of the customer service strategies. Hospital leaders can benefit from the patient and customer's feedback on the effectiveness of 
the strategies. Finally, further research can include focus group studies with hospital staff discussing the strategies and effectiveness of the strategies for customer service. A focus group could provide further details and a cohesive view of the strategies use for customer service.

\section{Limitations}

Simon and Goes (2013) [12] described limitations as issues out of the researchers' control, and potential weaknesses of the study. The study limitations were hospital managers in healthcare. Data did not come from the wide range of other professionals in healthcare for example, nurses, doctors, therapist, and clinicians. The study did not include the customers and patients who will benefit from excellent customer service. Another limitation was the small sample size of hospital managers. The research focus was on the strategies that hospital managers use to ensure employees are delivering excellent customer service to customers and patients; many other factors existed to explore. The research limitation was in qualitative research using interviews as opposed to other methods, for example, focus groups, or discussions as other options to report on customer service. The study has limitation to a hospital system in Nevada with three hospitals.

\section{Conclusions}

Creating an exceptional patient and customer experience in hospitals is an effort that must include involvement from hospital leaders, managers, contractors, and staff. Hospital leaders need to set goals and strategies for quick implementation with short-term results and long-term effects of satisfaction. Achieving patient satisfaction is not only ethical but also necessary to achieve high scores on the HCAHPS survey and receive reimbursement for the hospital system [66]. Hospital managers must create and analyze strategies that can accomplish set goals and deliver proper results. Acquiring a better understanding of strategies for customer service should help increase customer satisfaction and increase the growth of loyal and trusting customers for the hospital system. The Center for Medicare and Medicaid Services hospital payment reimbursements based on HCAHPS scores forced hospital decision makers to pay closer attention to customer service and support the idea of implementing new strategies for long-term customer satisfaction [67].

Sustaining knowledge and a better understanding of customer service strategies should assist hospital managers in improving customer satisfaction, patient experience, and revenue generation for the hospital. The HCAHPS scores and their importance to hospital reimbursements generate the need for all hospital staff to practice strategies for customer service [96]. Several strategies emerged for the improvement of customer service in hospitals. Interpersonal communication, hospital environment, and employee training were the three major strategies used to improve customer service in the hospital. Hospitals' staff exhibit 
satisfactory performance when customer expectations, regarding the quality of medical care and service satisfaction, receive confirmation (Gopal \& Bedi, 2014) [96]. Consistent review of the strategies in the daily operations of the hospital staff will enable hospital managers to continuously increase customer satisfaction and achieve the goal of reaching the $75 \%$ level or higher.

\section{Conflicts of Interest}

The authors declare no conflicts of interest regarding the publication of this paper.

\section{References}

[1] Joo, Y.J., Park, S. and Shin, E.K. (2017) Students' Expectation, Satisfaction, and Continuance Intention to Use Digital Textbooks. Computers in Human Behavior, 69, 83-90. https://doi.org/10.1016/j.chb.2016.12.025

[2] Hellen, K. and Saaksjarvi, M. (2011) Happy People Manage Better in Adverse Services. International Journal of Quality and Service Sciences, 3, 319-336. https://doi.org/10.1108/17566691111182861

[3] Ruddick, F. (2015) Customer Care in the NHS. Nursing Standard, 29, 37-42. https://doi.org/10.7748/ns.29.20.37.e8069

[4] Handa, M. and Gulati, A. (2014) Employee Engagement: Does Individual Personality Matter. Journal of Management Research, 14, 57-67. http://www.indianjournals.com/ijor.aspx?target=ijor:jmr\&type=home

[5] Suelflow, E. (2016) Systematic Literature Review: An Analysis of Administrative Strategies to Engage Providers in Hospital Quality Initiatives. Health Policy and Technology, 5, 2-17. https://doi.org/10.1016/j.hlpt.2015.10.001

[6] Scotti, D.J. and Harmon, J. (2014) Linkages between Organization Climate and Work Outcomes: Perceptual Differences among Health Service Professionals as a Function of Customer Contact Intensity. Journal of Health and Human Services Administration, 36, 417-459. http://jhhsa.spaef.org/articles

[7] Desir, D.R., Khanfar, N.M., Harrington, C. and Louden, D. (2011) The Value of Patient Care in the New Economy. Journal of Management and Strategy, 2, 23-27. https://doi.org/10.5430/jms.v2n2p23

[8] Miller, J. (2014) What's So Hard About Engaging People in Improving Their Workplace? Journal for Quality \& Participation, 37, 10-14. http://asq.org/pub/jqp/

[9] Alrubaiee, L. and Alkaaida, F. (2011) The Mediating Effect of Patient Satisfaction in the Patients Perceptions of Healthcare Quality-Patient Trust Relationship. International Journal of Marketing Studies, 3, 103-127. https://doi.org/10.5539/ijms.v3n1p103

[10] Sorenson, R., Paull, G., Magann, L. and Davis, J. (2013) Managing between the Agendas: Implementing Health Care Reform Policy in an Acute Care Hospital. Journal of Health Organization and Management, 27, 698-713. https://doi.org/10.1108/JHOM-11-2011-0119

[11] Choi, B.J. and Kim, H.S. (2013) The Impact of Outcome Quality, Interaction Quality, and Peer-to-Peer Quality on Customer Satisfaction with a Hospital Service. Managing Service Quality, 23, 188-204. https://doi.org/10.1108/09604521311312228

[12] Simon, M.K. and Goes, J. (2013) Dissertation and Scholarly Research: Recipes for 
Success. Dissertation Success, LLC, Seattle, WA.

[13] Drew, H. (2014) Overcoming barriers: Qualitative Interviews with German Elites. Electronic Journal of Business Research Methods, 12, 77-86.

http://www.ejbrm.com/main.html

[14] Devasagayam, R., Stark, N.R. and Valestin, L. (2013) Examining the Linearity of Customer Satisfaction: Return on Satisfaction as an Alternative. Business Perspectives \& Research, 1, 1-8.

http://www.somaiya.edu/VidyaVihar/simsr/Research_and_Pub/BPR

https://doi.org/10.1177/2278533720130201

[15] Cambra-Fierro, J., Melero, I. and Sese, F.J. (2015) Managing Complaints to Improve Customer Profitability. Journal of Retailing, 91, 109-124.

https://doi.org/10.1016/j.jretai.2014.09.004

[16] Cliff, B. (2012) Excellence in Patient Satisfaction within a Patient-Centered Culture. Journal of Healthcare Management, 57, 157-159.

https://www.ache.org/pubs/jhm/jhm_index.cfm https://doi.org/10.1097/00115514-201205000-00004

[17] Makarem, S.C. and Al-Amin, M. (2014) Beyond the Service Process: The Effects of Organizational and Market Factors on Customer Perceptions of Health Care Services. Journal of Service Research, 17, 399-414. https://doi.org/10.1177/1094670514541965

[18] Homisak, L. and Baum, N. (2015) Patient Satisfaction: What We Can Learn from Other Industries. The Journal of Medical Practice Management, 30, 294-298.

https://www.greenbranch.com/store/index.cfm/product/4_15/the-journal-of-medic al-practice-managementsupregsup.cfm

[19] Oliver, R.L. (1980) A Cognitive Model of the Antecedents and Consequences of Satisfaction Decisions. Journal of Marketing Research, 17, 460-469. https://doi.org/10.1177/002224378001700405

[20] Tsao, W. (2013) Application of Expectation Confirmation Theory to Consumers' Impulsive Purchase Behavior for Products Promoted by Showgirls in Exhibits. Journal of Promotion Management, 19, 283-298. https://doi.org/10.1080/10496491.2013.770811

[21] Ekiyor, A., Tengilimoglu, D., Yeniyurt, S. and Erturk, E. (2010) Relationship Marketing and Customer Loyalty: An Empirical Analysis in the Healthcare Industry. The Business Review Cambridge, 14, 244-249. http://www.jaabc.com/brcv14n2preview.html

[22] Khalaf, A.B., Rasli, A. and Ratyan, A.T. (2013) Building Customer Satisfaction from the Perspective of Employee Satisfaction. International Journal of Academic Research, 5, 297-301. https://doi.org/10.7813/2075-4124.2013/5-2/B.46

[23] Belias, D. and Koustelios, A. (2014) Organizational Culture and Job Satisfaction: A Review. International Review of Management and Marketing, 4, 132-149. https://doaj.org/

[24] Tahir, H., Waggett, C. and Hoffman, A. (2013) Antecedents of Customer Satisfaction: An E-CRM Framework. Journal of Business \& Behavioral Sciences, 25, 112-120. http://www.asbbs.org/jsbbs.html

[25] Chou, S.Y., Kiser, A.I.T. and Rodriguez, E.L. (2012) An Expectation Confirmation Perspective of Medical Tourism. Journal of Service Science Research, 4, 299-318. https://doi.org/10.1007/s12927-012-0012-3 
[26] Hsu, C. and Lin, J.C. (2015) What Drives Purchase Intention for Paid Mobile Apps? An Expectation Confirmation Model with Perceived Value. Electronic Commerce Research and Applications, 14, 46-57. https://doi.org/10.1016/j.elerap.2014.11.003

[27] Chen, K., Chang, F.-H. and Wu, C. (2013) Investigating the Wellness Tourism Factors in Hot Spring Hotel Customer Service. International Journal of Contemporary Hospitality Management, 25, 1092-1114. https://doi.org/10.1108/IJCHM-06-2012-0086

[28] Mathies, C. and Burford, M. (2011) Customer Service Understanding: Gender Differences of Frontline Employees. Journal of Service Theory and Practice, 21, 636-648. https://doi.org/10.1108/09604521111185628

[29] Lin, J.S.C. and Liang, H. (2011) The Influence of Service Environments on Customer Emotion and Service Outcomes. Managing Service Quality, 21, 350-372. https://doi.org/10.1108/09604521111146243

[30] Hawthorne, G., Sansoni, J., Hayes, L., Marosszeky, N. and Sansoni, E. (2014) Measuring Patient Satisfaction with Health Care Treatment Using the Short Assessment of Patient Satisfaction Measure Delivered Superior and Robust Satisfaction Estimates. Journal of Clinical Epidemiology, 67, 527-537. https://doi.org/10.1016/j.jclinepi.2013.12.010

[31] Tablan, F. (2016) A Catholic-Personalist Critique of Personalized Customer Service. Journal of Markets and Morality, 19, 99-119. http://www.marketsandmorality.com/index.php/mandm

[32] Kiessling, T., Isaksson, L. and Yasar, B. (2016) Market Orientation and CSR: Performance Implications. Journal of Business Ethics, 137, 269-284. https://doi.org/10.1007/s10551-015-2555-y

[33] Siu, N.Y. (2016) Customer Relationship Management and Recent Developments. Administrative Sciences, 6, 7. https://doi.org/10.3390/admsci6030007

[34] Green, P. (2014) Measuring Service Quality in Higher Education: A South African Case Study. Journal of International Education Research, 10, 131-142. http://www.cluteinstitute.com/journals/journal-of-international-education-research -jier/ https://doi.org/10.19030/jier.v10i2.8515

[35] Gummesson, E. (2014) Productivity, Quality and Relationship Marketing in Service Operations. International Journal of Contemporary Hospitality Management, 26, 656-662. https://doi.org/10.1108/IJCHM-01-2014-0017

[36] Kondasani, R.K.R. and Panda, R.K. (2015) Customer Perceived Service Quality, Satisfaction and Loyalty in Indian Private Healthcare. International Journal of Health Care Quality Assurance, 28, 452-467. https://doi.org/10.1108/IJHCQA-01-2015-0008

[37] Sutanto, J. and Minantyo, H. (2014) The Influence Service Quality Product Quality and Customer Satisfaction toward Customer Loyalty at Modern Riteil in East Java. International Journal of Academic Research, 6, 99-304.

[38] Oluseye, O.O., Tairat, B.T. and Emmanuel, J.O. (2014) Customer Relationship Management Approach and Student Satisfaction in Higher Education Marketing. Journal of Competitiveness, 6, 49-62. https://doi.org/10.7441/joc.2014.03.04

[39] Srisamran, P. and Ractham, V.V. (2014) Customer-Centric Knowledge Creation for Customer Relationship Management. Journal of Applied Business Research, 30, 397-408. 
http://www.cluteinstitute.com/journals/journal-of-applied-business-research-jabr/ https://doi.org/10.19030/jabr.v30i2.8410

[40] Carlson, J., Rahman, M.M., Rosenberger, P.J. and Holzmuller, H.H. (2016) Understanding Communal and Individual Customer Experiences in Group-Oriented Event Tourism: An Activity Theory Perspective. Journal of Marketing Management, 32, 900-925. https://doi.org/10.1080/0267257X.2016.1181099

[41] Negi, R. and Ketema, E. (2013) Customer-Perceived Relationship Quality and Satisfaction. African Journal of Economic and Management Studies, 4, 109-121. https://doi.org/10.1108/20400701311303186

[42] Narteh, B., Agbemabiese, G.C., Kodua, P. and Braimah, M. (2013) Relationship marketing and Customer Loyalty: Evidence from the Ghanaian Luxury Hotel Industry. Journal of Hospitality Marketing \& Management, 22, 407-436. https://doi.org/10.1080/19368623.2012.660564

[43] Shahraki, A.R. (2014) Evaluation of Customer Satisfaction about Bank Service Quality. International Journal of Industrial Mathematics, 6, 157-168. http://ijim.srbiau.ac.ir/

[44] Ali, S.H.S. and Ndubisi, N.O. (2011) The Effects of Respect and Rapport on Quality Perception of Customers of Small Healthcare Firms. Asia Pacific Journal of Marketing and Logistics, 23, 135-151. https://doi.org/10.1108/13555851111120452

[45] Graca, S.S., Barry, J.M. and Doney, P.M. (2015) Performance Outcomes of Behavioral Attributes in Buyer-Supplier Relationships. Journal of Business \& Industrial Marketing, 30, 805-816. https://doi.org/10.1108/JBIM-04-2014-0072

[46] Bowen, J.T. and McCain, S.C. (2015) Transitioning Loyalty Programs: A Commentary on the Relationship between Customer Loyalty and Customer Satisfaction. International Journal of Contemporary Hospitality Management, 27, 415-430. https://doi.org/10.1108/IJCHM-07-2014-0368

[47] Calin, G. (2013) Factors Influencing Customers' Behavior towards Trusted Service Providers: An Investigation of Four Service Settings. Annals of the University of Oradea: Economic Science, 22, 1753-1764. http://anale.steconomiceuoradea.ro/en/

[48] Loo, P.T., Boo, H.C. and Khoo-Lattimore, C. (2013) Profiling Service Failure and Customer Online Complaint Motives in the Case of Single Failure and Double Deviation. Journal of Hospitality Marketing \& Management, 22, 728-751.

http://www.tandfonline.com/loi/whmm20\#.Ve9lh8uFOUk https://doi.org/10.1080/19368623.2013.724373

[49] Chen, Z., Zhu, J. and Zhou, M. (2015) How Does a Servant Leader Fuel the Service fire? A Multi-Level Model of Servant Leadership, Individual Self-Identity, Group Competition Climate, and Customer Service Performance. Journal of Applied Psychology, 100, 511-521. https://doi.org/10.1037/a0038036

[50] Rijal, S. (2016) Leadership Style and Organizational Culture in Learning Organization: A Comparative Study. International Journal of Management \& Information Systems, 20, 17-25. https://doi.org/10.19030/ijmis.v20i2.9642

[51] Liu, C., Liu, X. and Geng, Z. (2013) Emotional Labor Strategies and Service Performance: The Mediating Role of Employee Creativity. Journal of Applied Business Research, 29, 1583-1996.

http://www.cluteinstitute.com/journals/journal-of-applied-business-research-jabr/ https://doi.org/10.19030/jabr.v29i5.8076

[52] Almutawa, Z., Muenjohn, N. and Zhang, J. (2016) The Effect of Human Resource 
Management System on Employees' Commitment: The Mediating Role of the Amo Model. The Journal of Developing Areas, 50, 17-29. https://doi.org/10.1353/jda.2016.0147

[53] Ponsignon, F., Smart, A., Williams, M. and Hall, J. (2015) Healthcare Experience Quality: An Empirical Exploration Using Content Analysis Techniques. Journal of Service Management, 26, 460-485. https://doi.org/10.1108/JOSM-10-2014-0265

[54] Prentice, C. (2013) Service Quality Perceptions and Customer Loyalty in Casinos. International Journal of Contemporary Hospitality Management, 25, 49-64. https://doi.org/10.1108/09596111311290219

[55] U.S. Bureau of Labor Statistics (2019) Employment Projections-2018-2028. http://www.bls.gov/news.release/pdf/ecopro.pdf

[56] Gounaris, S. and Boukis, A. (2013) The Role of Employee Job Satisfaction in Strengthening Customer Repurchase Intentions. The Journal of Services Marketing, 27, 322-333. https://doi.org/10.1108/08876041311330799

[57] Murale, V., Singh, J. and Preetha, R. (2015) Employee Commitment and Patient Satisfaction: An Initial Reflection from Indian Healthcare Sector. International Journal on Customer Relations, 3, 22-30. https://doi.org/10.21863/ijcr/2015.3.1.004

[58] Giovanis, A., Athanasopoulou, P. and Tsoukatos, E. (2015) The Role of Service Fairness in the Service Quality-Relationship Quality-Customer Loyalty Chain. Journal of Service Theory and Practice, 25, 744-776. https://doi.org/10.1108/JSTP-11-2013-0263

[59] Delcourt, C., Gremler, D.D., Van Riel, A.C.R. and Van Birgelen, M. (2013) Effects of Perceived Employee Emotional Competence on Customer Satisfaction and Loyalty. The Mediating Role of Rapport. Journal of Service Management, 24, 5-24. https://doi.org/10.1108/09564231311304161

[60] Iqbal, A. (2014) Effect of Relationship Quality on Customer Loyalty. International Journal of Information, Business and Management, 6, 41-52. http://ijibm.elitehall.com/index.htm

[61] Kursunluoglu, E. (2014) Shopping Centre Customer Service: Creating Customer Satisfaction and Loyalty. Marketing Intelligence and Planning, 32, 528-548. https://doi.org/10.1108/MIP-11-2012-0134

[62] Pflueger, D. (2016) Knowing Patients: The Customer Survey and the Changing Margins of Accounting in Healthcare. Accounting, Organizations and Society, 53, 17-33. https://doi.org/10.1016/j.aos.2016.08.002

[63] Richard, J.E. and Zhang, A. (2012) Corporate Image, Loyalty, and Commitment in the Consumer Travel Industry. Journal of Marketing Management, 28, 568-593. https://doi.org/10.1080/0267257X.2010.549195

[64] Itumalla, R. (2012) A Study on Service Quality in Healthcare. International Journal of Management Research and Review, 2, 308-315. http://ijmrr.com/

[65] Rangachari, P., Bhat, A. and Yoon, S. (2011) Using the Customer Service Framework to Successfully Implement Patient and Family Centered Care. Quality Management in Health Care, 20, 179-197. https://doi.org/10.1097/QMH.0b013e31822089a3

[66] Dockins, J., Abuzahrieh, R. and Stack, M. (2015) Arabic Translation and Adaptation of Healthcare Providers and Systems (HCAHPS) Patient Satisfaction Survey Instrument. Journal of Health \& Human Services Administration, 37, 518-536. https://jhhsa.spaef.org/search.php 
[67] Kahn, S.A., Iannuzzi, J.C., Stassen, N.A., Bankey, P.E. and Gestring, M. (2015) Measuring Satisfaction: Factors That Drive Hospital Consumer Assessment of Healthcare Providers and Systems Survey Responses in a Trauma and Acute Care Surgery Population. American Surgeon, 81, 537-543. https://www.ingentaconnect.com/content/sesc/tas

[68] Khan, M.T., Humayun, A.A. and Sajjad, M. (2015) Factors Affecting Impulse Buying and Percentage of Impulse Buying in Total Purchasing. International Journal of Information, Business and Management, 7, 254-268.

http://ijibm.elitehall.com/index4.htm

[69] Kim, R.H., Gaukler, G.M. and Lee, C.W. (2016) Improving Healthcare Quality: A Technological and Managerial Innovation Perspective. Technological Forecasting \& Social Change, 113, 373-378. https://doi.org/10.1016/j.techfore.2016.09.012

[70] Vogus, T.J. and McClelland, L.E. (2016) When the Customer Is the Patient: Lessons from Healthcare Research on Patient Satisfaction and Service Quality Ratings. $\mathrm{Hu}$ man Resource Management Review, 26, 37-49. https://doi.org/10.1016/j.hrmr.2015.09.005

[71] Sinkovics, R.R. and Alfoldi, E.A. (2012) Progressive Focusing and Trustworthiness in Qualitative Research: The Enabling Role of Computer-Assisted Qualitative Data Analysis Software (CAQDAS). Management International Review, 52, 817-845. https://doi.org/10.1007/s11575-012-0140-5

[72] Ranney, M.L., Meisel, Z.F., Choo, E.K., Garro, A.C., Sasson, C. and Morrow Guthrie, K. (2015) Interview-Based Qualitative Research in Emergency Care Part II: Data Collection, Analysis and Results Reporting. Academic Emergency Medicine, 22, 1103-1112. https://doi.org/10.1111/acem.12735

[73] Yin, R.K. (2014) Case Study Research, Designs and Methods. 5th Edition, Sage Publications, Thousand Oaks, CA.

[74] Lalor, J.G., Casey, D., Elliott, N., Coyne, I., Comiskey, C., Higgins, A. and Begley, C. (2013) Using Case Study within a Sequential Explanatory Design to Evaluate the Impact of Specialist and Advanced Practice Roles on Clinical Outcomes: The SCAPE Study. BMC Medical Research Methodology, 13, 55. https://doi.org/10.1186/1471-2288-13-55

[75] McCusker, K. and Gunaydin, S. (2015) Research Using Qualitative, Quantitative or Mixed Methods and Choice Based on the Research. Perfusion, 30, 537-542. https://doi.org/10.1177/0267659114559116

[76] Mollick, E. (2014) The Dynamics of Crowdfunding: An Exploratory Study. Journal of Business Venturing, 29, 1-6. https://doi.org/10.1016/j.jbusvent.2013.06.005

[77] Barratt, M.J., Ferris, J.A. and Lenton, S. (2015) Hidden Populations, Online Purposive Sampling, and External Validity: Taking off the Blindfold Abstract. Field $\mathrm{Me}$ thods, 27, 3-21. https://doi.org/10.1177/1525822X14526838

[78] Jacob, S.A. and Furgerson, S.P. (2012) Writing Interview Protocols and Conducting Interviews: Tips for Students New to the Field of Qualitative Research. The Qualitative Report, 17, 1-10. http://www.nova.edu/ssss/QR/QR17/17_42.html

[79] Hansman, C.A. (2015) Training Librarians as Qualitative Researchers: Developing Skills and Knowledge. The Reference Librarian, 56, 274-294. https://doi.org/10.1080/02763877.2015.1057683

[80] Mojtahed, R., Nunes, M.B., Martins, J.T. and Peng, A. (2014) Equipping the Constructivist Researcher: The Combined Use of Semi-Structured Interviews and Decision-Making Maps. Electronic Journal of Business Research Methods, 12, 87-95. 
http://www.ejbrm.com

[81] Fisher, J.A. (2013) Expanding the Frame of Voluntariness in Informed Consent: Structural Coercion and the Power of Social and Economic Context. Kennedy Institute of Ethics Journal, 23, 355-379. http://muse.jhu.edu/journal/107 https://doi.org/10.1353/ken.2013.0018

[82] DeLyser, D., Potter, A., Chaney, J., Crider, S., Debnam, I., Hanks, G. and Seemann, J. (2013) Teaching Qualitative Research: Experiential Learning in Group-Based Interviews and Coding Assignments. Journal of Geography, 112, 18-28.

https://doi.org/10.1080/00221341.2012.674546

[83] Vohra, V. (2014) Using the Multiple Case Study Design to Decipher Contextual Leadership Behaviors in Indian Organizations. Electronic Journal of Business Research Methods, 12, 54-65. http://www.ejbrm.com/main.html

[84] Mohamadzadeh, Z., Mortazavi, S., Lagzian, M. and Rahimnia, F. (2015) Toward an Exploration of Follower's Implicit Followership Theories of Mashhad's Large Organizations Using a Qualitative Approach. Iranian Journal of Management Studies, 8, 397-419. https://ijms.ut.ac.ir/

[85] Mangioni, V. and McKerchar, M. (2013) Strengthening the Validity and Reliability of the Focus Group as a Method in Tax Research. Ejournal of Tax Research, 11, 176-190. https://www.business.unsw.edu.au/research/research-journals/atax-journal

[86] Harvey, L. (2015) Beyond Member-Checking: A Dialogic Approach to the Research Interview. International Journal of Research \& Method in Education, 38, 23-38. https://doi.org/10.1080/1743727X.2014.914487

[87] Cope, D.G. (2014) Methods and Meanings: Credibility and Trustworthiness of Qualitative Research. Oncology Nursing Forum, 41, 89-91. https://doi.org/10.1188/14.ONF.89-91

[88] Grill, C., Ahlborg Jr., G. and Wikstrom, E. (2014) Health Care Managers Learning by Listening to Subordinates' Dialogue Training. Journal of Health Organization and Management, 28, 437-454. https://doi.org/10.1108/JHOM-01-2013-0010

[89] Hsu, C., Chang, C., Huang, H. and Chiang, C. (2011) The Relationships among Social Capital, Organizational Commitment and Customer-Oriented Pro-Social Behavior of Hospital Nurses. Journal of Clinical Nursing, 20, 1383-1392. https://doi.org/10.1111/j.1365-2702.2010.03672.x

[90] Blair, E. (2014) Safety Interventions: Strategies for Effective Design. Professional Safety, 59, 50-55. https://www.asse.org

[91] Conduit, J., Matanda, M.J. and Mavondo, F.T. (2014) Balancing the Act: The Implications of Jointly Pursuing Internal Customer Orientation and External Customer Orientation. Journal of Marketing Management, 13-14, 1320-1352. https://doi.org/10.1080/0267257X.2014.909513

[92] Gabriel, A.S., Acosta, J.D. and Grandey, A.A. (2015) The Value of a Smile: Does Emotional Performance Matter More in Familiar or Unfamiliar Exchanges? Journal of Business and Psychology, 30, 37-50. https://doi.org/10.1007/s10869-013-9329-2

[93] U.S. Centers for Medicare \& Medicaid Services (2016) Medicare.gov. https://www.mymedicare.gov/

[94] Oghuma, A.P., Libaque-Saenz, C.F., Wong, S.F. and Chang, Y. (2016) An Expectation-Confirmation Model of Continuance Intention to Use Mobile Instant Messaging. Telematics and Informatics, 33, 34-47. https://doi.org/10.1016/j.tele.2015.05.006 
[95] Wu, J. (2015) Internal Audit and Review of the Negative Customer Behavior. Journal of Service Science and Management, 8, 578-587.

https://doi.org/10.4236/jssm.2015.84058

[96] Gopal, R. and Bedi, S.S. (2014) Impact of Hospital Services on Outpatient Satisfaction. International Journal of Research in Business Management, 2, 37-44.

http://www.impactjournals.us 